\title{
XYZ-Stars i Solar System Pathway: una experièn- cia museística de treball per projectes sobre les constel-lacions i el Sistema Solar
}

\author{
Xavier Domènech (xdomene2@xtec.cat) Institut de Granollers \\ Isabel Llorente (illorent@xtec.cat), Institut de Granollers \\ Neus Ruiz (nruiz12@xtec.cat) Institut de Granollers \\ Carles Serra (cserramail@gmail.com) Institut de Granollers \\ Maria Ulldemolins (mulldemolinsurrea@gmail.com) Institut de Granollers \\ Antoni Arrizabalaga (m.granollers.cn@diba.cat) Museu de Ciències Naturals de Granollers \\ Jordi Domènech-Casal (jdomen44@xtec.cat) Institut de Granollers i Grup LIEC, Departament de Didàctica \\ de les Matemàtiques i les Ciències, Universitat Autònoma de Barcelona (UAB)
}

L'alumnat de secundària sol presentar concepcions errònies relatives a les dimensions $i$ proporcions de l'Univers $i$ els cossos celests. Les metodologies actives (com el treball per projectes) suposen una oportunitat per a ubicar aquestes concepcions en el marc d'un conflicte cognitiu. Es descriuen dues experiències interdisciplinars de treball per projectes sobre les constel/lacions i el Sistema Solar. Les experiències s'han dut a terme com a projecte trimestral en col•laboració amb el Museu de Ciències Naturals de Granollers, $i$ ha resultat en una exposició oberta al públic de les produccions dels alumnes en una sala del museu $i$ en forma de maqueta urbana de $10 \mathrm{~km}$. Els resultats de l'aplicació es descriuen juntament amb una valoració per a orientar el desenvolupament de projectes trimestrals.

Paraules clau: Constel•lacions, astronomia, Treball per Projectes, Sistema Solar, Museu

High school students usually present misconceptions related with the dimensions and proportions of the Univers and celestials bodies. Active methodologies (as project work) represent an opportunity to put these misconceptions in a situation of a cognitive conflict. In this article, it has been described two interdisciplinary experiences of project work about the constellations and the Solar system. The experiences have been developed as a quarterly project with the collaboration of Natural Science Museum of Granollers, and as a result it has been done an exhibition open to the public about students' productions in a room of the museum as a urban model. The results of the applications have been described together with an assessment to guide the development of quarterly projects.

Keywords: constellations, astronomy, project work, Solar system, museum

\section{INTRODUCCIÓ}

\section{L'ensenyament de l'astronomia a Se- cundària}

L'astronomia ha ocupat un espai tradicionalment poc significatiu al currículum de l'Educació Secundària. Habitualment ubicada a 1er d'ESO, els seus continguts han limitat habitualment el seu abast al Sistema Solar (Carmona, 1994, García, 2014), repetint en la pràctica continguts que els alumnes ja han tractat a Primària, com la ubicació i característiques principals de planetes o satèl•lits, efectes quotidians d'àmbit planetari com les marees, estacions i fases de la Lluna (Vílchez-González i Ramos-Tamajón, 2015, González, García i Martínez, 2015) i, com a 
molt, tipus de cossos celests menors (meteorits, cometes...). En les representacions escolars usades als llibres de text, la mida dels planetes i les distàncies entre ells estan a escales diferents, el que promou la idea de que els planetes estan, en realitat, molt propers els uns als altres, a més d'altres concepcions errònies (Solbes y Palomar, 2011).

Fora del Sistema Solar, els alumnes solen treballar les constel-lacions des del punt de vista de la seva ubicació a la cúpula celest i efectes de la rotació terrestre en el seu posicionament, el que alimenta una visió "Planetari 2D" i una concepció errònia de que les estrelles es troben totes en un mateix espai "allà dalt", i alimentant una concepció "Sistema-Solar-Cèntrica" de l'Univers (Domínguez i Varela, 2008, Leite i Hosoume, 2009).

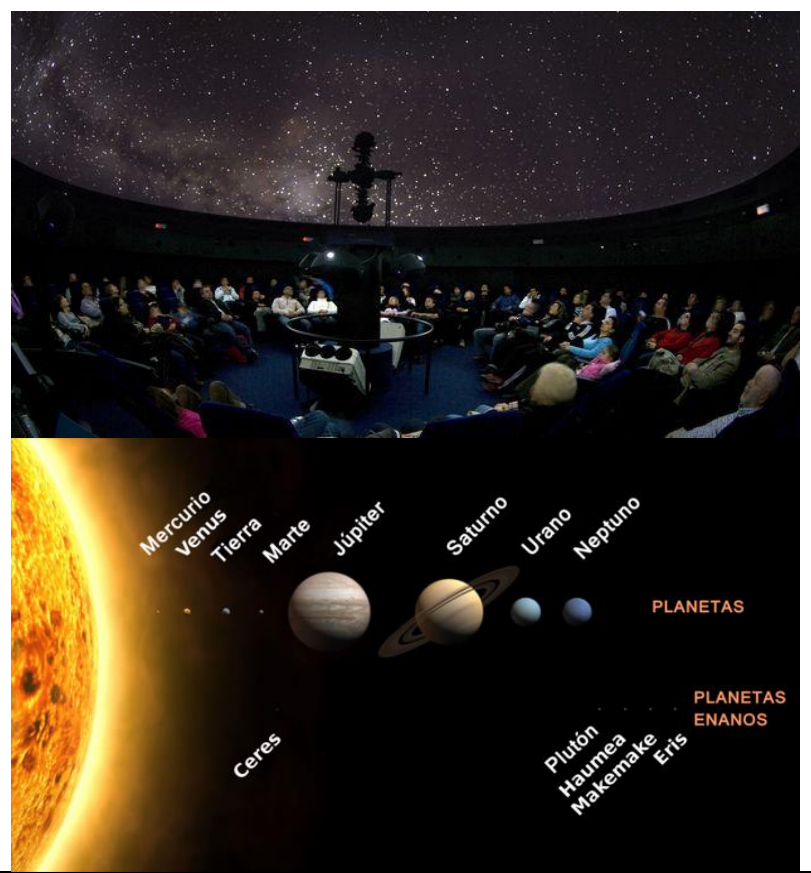

Figura 1: Cúpula d'un planetari i representació del Sistema Solar similar a la d'un llibre de text. Ambdós suports didàctics promouen involuntàriament concepcions errònies sobre l'Univers i el Sistema Solar.

Com a resultat, els alumnes tenen una visió esbiaixada del Sistema Solar i poc coneixement de l'estructura de la nostra Galàxia o de l'Univers (Alfonso et al, 1995, Palomar, 2013) i, en general, poca percepció de la vastitud de l'Univers.

La proposta LOMCE suposa un pas en la bona direcció, ja que tot i mantenir una astronomia centrada en el sistema Sol-Terra-Lluna a 1er d'ESO (amb un sol ítem extra-solar, dedicat a les teories sobre l'origen de l'Univers), incorpora a la matèria de
Cultura Científica de 4t d'ESO un bloc sencer dedicat a ítems astronòmics més actualitzats, referits, per exemple, a l'estructura de l'Univers més enllà del Sistema Solar, els forats negres i les condicions per a la vida en altres planetes.

\section{Les concepcions alternatives i les metodologies actives en el treball amb l’astronomia}

Diversos autors consideren que en l'ensenyament de l'astronomia és particularment difícil canviar concepcions alternatives prèvies de l'alumnat (geocentrisme, funcionament de les estacions, confusions amb l'astrologia) (Carmona, 1994, Domínguez i Varela, 2009, Varela et al, 2012, Navarro, 2011), i que això és degut en part a les escales i dimensions que dificulten modelitzar els esdeveniments astronòmics per una banda, i les concepcions alternatives promogudes per el mateix professorat o materials educatius (Solbes y Palomar, 2011, Varela et al, 2012, García, 2014). El treball descriptiu a l'aula no permet incidir en aquestes concepcions errònies, que es reprodueixen cursos després. En canvi, el treball amb activitats manipulatives o de caire sòcioconstruccionista que impliquin un conflicte cognitiu i discussió en el marc d'un context rellevant poden ser de més utilitat per canviar aquestes concepcions prèvies recalcitrants (Pozo y Gómez 2010, García, 2014, Palomar y Solbes, 2015).

\section{Marcs metodològics}

En aquest sentit, les propostes metodològiques de l'Aprenentatge Basat en Projectes suposen una oportunitat de posar l'alumne al centre del procés d'aprenentatge i promoure a l'aula mecanismes de discussió i construcció social del coneixement que impactin més fortament en aquestes concepcions prèvies. En particular, sense pretensió d'establir-ne una definició complerta (que els lectors podran trobar en altres autors (Grau, 2010, Majó i Baqueró, 2014), els autors entenem per treball per projectes les seqüències didàctiques en què:

- Existeix un objectiu extern (i concomitant) a l'aprenentatge.

- Existeix un context i un conflicte que instrumentalitza el currículum.

- S'usen metodologies actives i treball en comunitat d'aprenentatge.

- Es genera un producte final.

El camp de l'astronomia, per les magnituds dels fenòmens i les complexitats dels estris propis de l'àrea, és un camp en el que els treballs i projectes 
requereixen l'elaboració d'un producte extern a la disciplina. En aquest sentit, orientar el disseny dels projectes d'Aprenentatge Basat en Projectes cap a la línia de l'Aprenentatge- Servei ens ha servit per a proposar una orientació cultural dels projectes d'astronomia, en particular, la creació de productes museístics en un museu real i amb una exposició i aprofitant el potencial que ofereixen els Museus Virtuals de participació dels usuaris i catalogació de continguts (Domènech-Casal, 2013).

\section{OBJECTIUS}

El nostre objectiu va ser elaborar una proposta d'ABP que permetés treballar les següents concepcions errònies en astronomia:

\begin{tabular}{|c|c|}
\hline Què solen creure els alumnes & Quina concepció volem generar \\
\hline $\begin{array}{l}\text { Els planetes del Sistema Solar } \\
\text { són enormes i molt propers en- } \\
\text { tre si. }\end{array}$ & $\begin{array}{l}\text { Hi ha una gran distància entre els } \\
\text { planetes, que, comparativament a } \\
\text { les distàncies que els separen, són } \\
\text { molt petits. }\end{array}$ \\
\hline $\begin{array}{l}\text { L'espai és ple de cossos ce- } \\
\text { lests. }\end{array}$ & L'espai està fonamentalment buit. \\
\hline $\begin{array}{l}\text { Les estrelles formen una cú- } \\
\text { pula al cel i són totes en un ma- } \\
\text { teix espai, el Cel. }\end{array}$ & $\begin{array}{l}\text { Les estrelles són a diferents distàn- } \\
\text { cies i no formen cap cúpula, sinó un } \\
\text { espai profund on nosaltres i la nos- } \\
\text { tra estrella estem situats. }\end{array}$ \\
\hline
\end{tabular}

\section{DISSENY I APLICACIÓ DE LES ACTIVI-} TATS

L'activitat que es presenta ha estat elaborada i aplicada el curs 2015-2016 amb els 58 alumnes de 1er d'ESO de l'Institut de Granollers, institut de nova creació que té com a eixos pedagògics -entre d'altres- el Treball per Projectes i l'accent en la Ciència i la Tecnologia. La programació didàctica anual inclou la realització de 3 projectes inter-disciplinars trimestrals en els que un cop cada trimestre durant una setmana-10 dies, s'abandona la distribució horària per matèries i es treballa exclusivament en activitats del projecte, de manera que els diferents professors passen per les diferents aules acompanyant els alumnes en les diferents etapes del projecte. L'activitat proposada està formada per dos projectes, que conflueixen en la creació d'una exposició cultural. Les diferents tasques dels dos projectes són disponibles en sengles webs creades ad hoc [1].

\section{Solar System Pathway: Un Sistema Solar a la teva ciutat. Un planeta a la teva butxaca}

El producte: Es proposa als alumnes la construcció d'un passeig-maqueta urbana que representi el Sistema Solar (des del Sol al Cinturó de Kuiper) en un recorregut urbà de $10 \mathrm{~km}$, de manera que en aquest itinerari, el passejant parteix de l'inici (representat per el Sol) i es troba al llarg del recorregut els diversos planetes ubicats al lloc que ocuparien i representats en un panell físic a la mida que tindrien. Cada panell conté a més un codi QR que condueix a una descripció divulgativa sobre el planeta creada per els alumnes ubicada en una pàgina web creada ad hoc. Produccions dels alumnes són disponibles per a la seva consulta a la web del projecte: http://solarsystempathway.museugranollersciencies.org/.

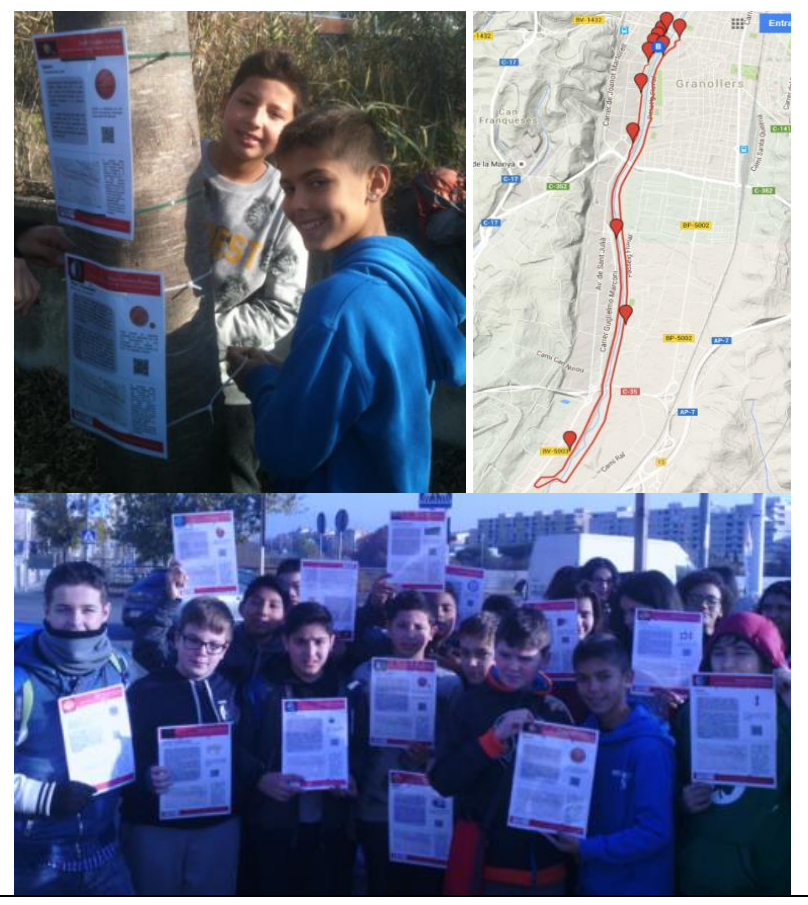

Figura 2: Els alumnes creen panells físics amb informacions sobre la mida que tindria el cos celest en aquest recorregut i l'ubiquen en el lloc que ocuparia. Cada panell conté també una breu presentació del cos celest i un codi QR que condueix a continguts digitals ampliats creats per l'alumnat.

El procés: Hem repartit 21 cossos celests (incloent planetes, satèl•lits,..) del Sistema Solar entre els alumnes, agrupats en equips de 203 . Cada equip ha seguit els mateixos passos sobre el seu cos celest:

1) Cercar la distància i mida i fer el càlcul de les proporcions per a determinar la posició i mida en la maqueta de $10 \mathrm{~km}$ i cercar les coordenades al mapa de l'itinerari.

2) Cercar informació sobre diferents aspectes del seu cos celest (referents històrics o mitològics, 
missions d'investigació científica, característiques,...) i redactar-la en format divulgatiu.

3) Elaborar un panell físic per a ubicar en l'itinerari (amb una breu descripció i representació de la mida) i un panell virtual divulgatiu sobre el cos celest en un Museu Virtual vinculat des del panell físic mitjançant un codi QR. Ubicar el panell físic i publicar el panell virtual.

\section{XYZStars. Constel•lacions: qüestió de perspectiva}

El producte: Es proposa als alumnes l'elaboració d'una exposició de maquetes de les constel•lacions principals en 3 dimensions, de manera que es puguin apreciar les diferents distàncies de cadascuna de les estrelles que les formen i també representades mitjançant colors i mides les diferències entre les d'estrelles (mida, temperatura, tipus espectral). En observar la maqueta des del davant, es veu projectada la constel•lació, però en desplaçar-se l'observador, pel canvi de perspectiva, les constel-lacions adopten noves configuracions. Produccions dels alumnes són disponibles a la web del centre educatiu:

https://agora.xtec.cat/institutgranollers/general/21de-desembre-inauguracio-xyz-stars/

El procés: Hem repartit 30 constel-lacions dels hemisferis Nord i Sud entre els alumnes, agrupats per parelles. Cada parella ha seguit els mateixos passos sobre la seva constel•lació:

1) Cercar la distància i característiques de les diferents estrelles mitjançant el programa de simulació astronòmica Stellarium [2].

2) Fer els càlculs per a determinar a quina profunditat s'ha d'ubicar cada estrella en un espai de 50 $\mathrm{cm}$ (profunditat de la maqueta), en proporció a la seva distància del nostre Sol.

3) Representar cada estrella (mida qualitativa, color) i ubicar-la a la seva posició en la maqueta, de manera que observant a 1 metre de distància es projecti la constel•lació al fons. Elaborar la maqueta.

4) Elaborar un pòster divulgatiu sobre la constel•lació fent referència a aspectes històrics, mitològics i científics.

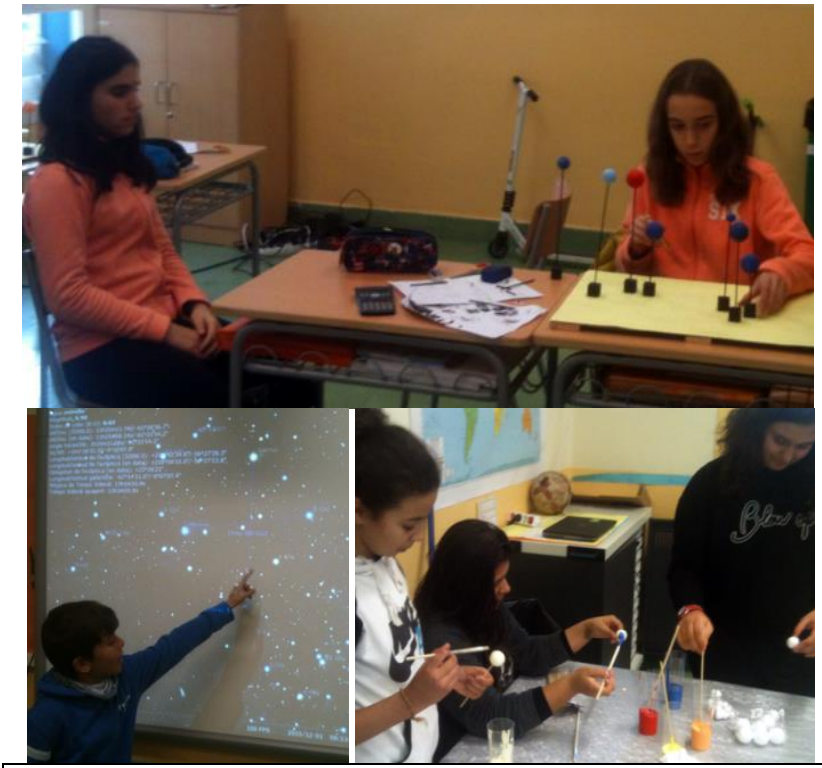

Figura 3: Els alumnes cerquen mitjançant programes informàtics informació sobre les estrelles que formen les constel-lacions i les representen segons la seva tipologia i ubiquen segons la distància respecte a la Terra.

\section{Exposició astronòmica al Museu La Tela de Granollers}

El procés: Amb anterioritat al projecte, a finals del curs 2014-2015, durant la preparació prèvia del projecte de Centre i dels projectes trimestrals, una comissió formada per els professors de Ciències i la directora del centre vam contactar el Museu de $\mathrm{Ci}$ ències Naturals de Granollers amb la intenció de proposar-los que els projectes XYZStars i SolarSystemPathway es presentessin i s'exposessin al museu, que allotjaria també al seu servidor web la web del projecte SolarSystemPathway. Davant la bona disposició del museu, en una segona trobada al novembre de 2015, alumnes encarregats es van ocupar de trobar-se de nou amb el director del museu per a rebre'n l'encàrrec "formal" des del mateix museu i concretar detalls. A partir d'aquí es va iniciar la tasca de creació dels productes (els associats als dos projectes) i l'organització de la inauguració per part dels alumnes que van elaborar els discursos d'inauguració, van distribuir-se responsabilitats organitzatives de l'acte (acollida, guia, comissari) i van fer difusió entre les escoles de Primària. 


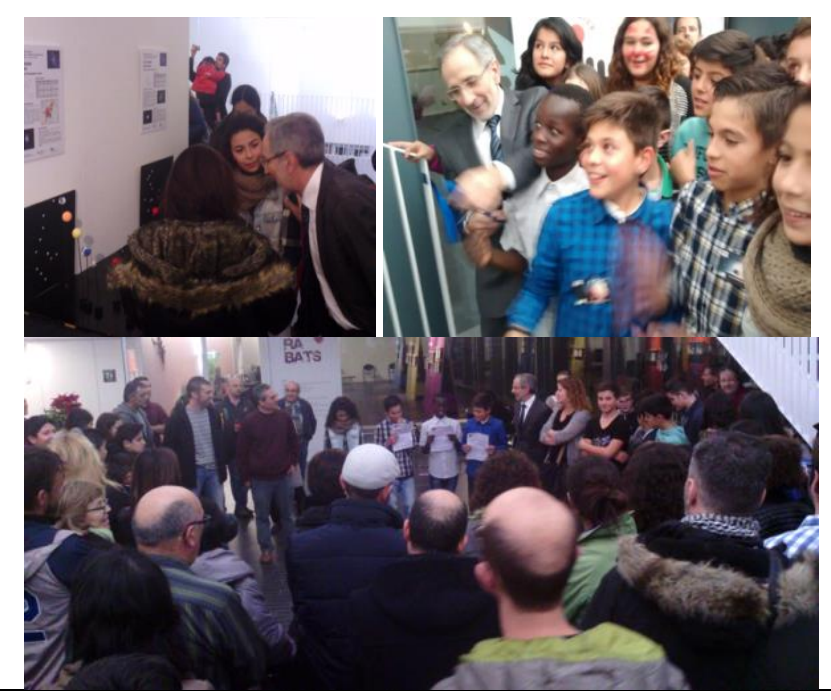

Figura 4: Imatges de l'exposició al Museu i la seva inauguració amb presència de les autoritats locals.

El producte: el resultat final del treball dels alumnes ha estat una exposició de divulgació científica al Museu de Ciències Naturals de Granollers que posa l'accent en les concepcions errònies comentades a la introducció. En la realització final ha estat important pels alumnes que el seu treball acabés exposat en una sala d'un museu, en les converses d'aquests amb els responsables del museu es va parlar molt sobre la importància de les presentacions i dels acabats finals per un treball d'aquestes característiques. L'organització del muntatge "in situ" a la sala del museu també va ser realitzat per l'alumnat amb ajuda dels tècnics del museu; les tasques es van repartir en petits grups d'alumnes amb molt bona implicació de la majoria de tots ells. L'exposició, que va ser objecte d'atenció mediàtica [3], es va inaugurar al museu el dia 21 de desembre de 2015 i va romandre oberta dos mesos, fins a finals de febrer de 2016.

\section{RESULTATS}

L'exposició ha estat oberta al públic durant dos mesos amb una fluència de públic de 2.144 visitants. Entre les valoracions més comunes del públic ha estat la sorpresa de trobar una exposició muntada per alumnes d'un institut $\mathrm{i}$ amb la qualitat més que notable. Des del museu s'ha valorat especialment la qualitat final, valorada com ja hem dit pel mateix públic, i l'oportunitat de mostrar i compartir tots els processos que impliquen el muntatge d'una exposició.

L'exposició va ser un èxit i els alumnes es mostraren molt satisfets de la feina feta, no només pel procés, sinó també pels aprenentatges. En paraules de Jordi A., un dels alumnes en l'entrevista que li va fer el diari local 9Nou: "He après noves constel•lacions que no coneixia, però no només he après això. He fet també moltes matemàtiques, he après a buscar informació, o obligar-me a entendre-la per a escriure-la amb les meves paraules, a fer un pòster, a utilitzar noves eines que no sabia fer servir, a fer codis QR, a publicar en una web...". A més, el fet de participar en una activitat d'aquest tipus (impacte extern, producte real), va col•laborar a generar un impacte en els alumnes, tal com descriu l'alumne Carlos B. al mateix mitjà: "Ha estat una experiència que mai se m'oblidarà. M'ha agradat molt".

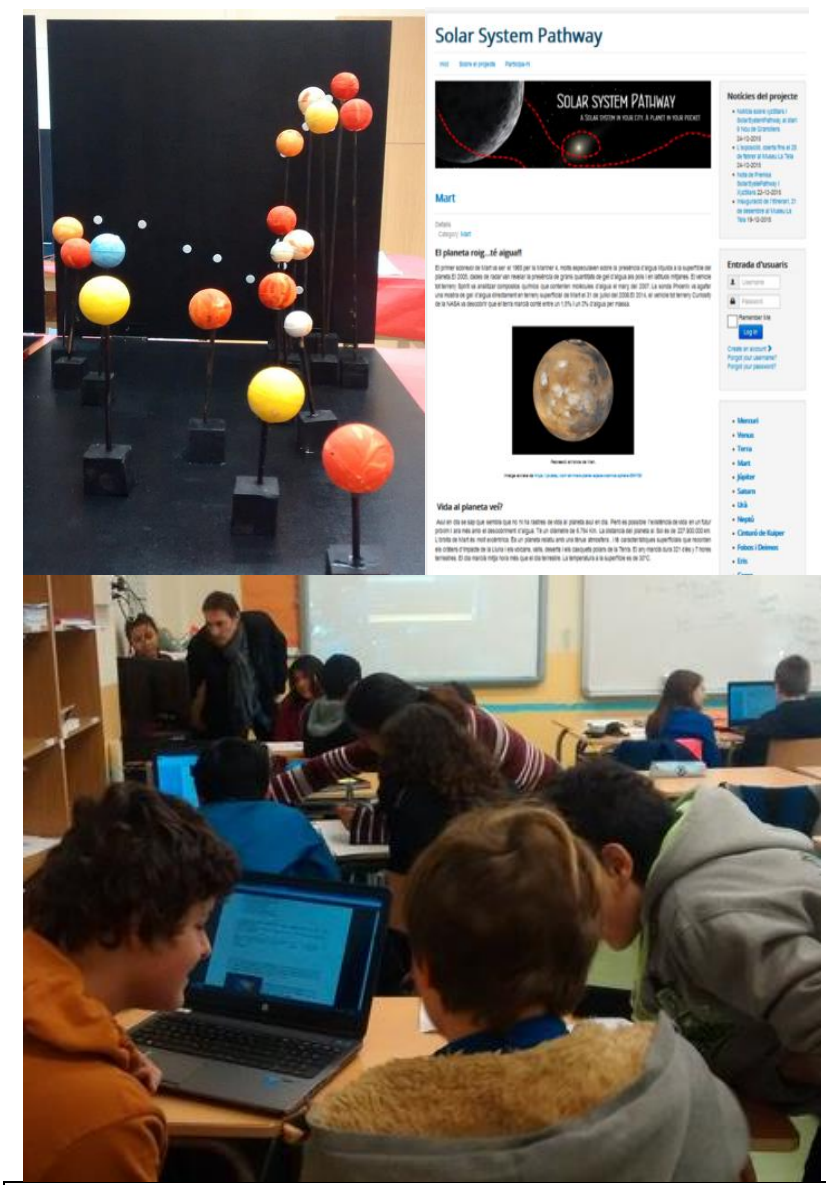

Figura 5: Dos productes finals dels projectes (maqueta d'una constel•lació i panell virtual d'un planeta, i alumnes treballant col-laborativament a l'aula amb el suport de dos professors.

Al llarg del projecte va ser necessari refer diverses vegades la planificació inicial per manca de temps i redefinir-ne aspectes tècnics, cosa que va implicar reunions de coordinació de professorat improvisades i una certa sobrecàrrega de tasques.

Pel que fa a la implicació dels alumnes, el projecte va desencadenar situacions d'interès: determinats alumnes amb dificultats per seguir enfocs més 
convencionals es van implicar fins al punt de dedicar-se a ajudar altres companys a assolir els seus objectius. D'altra banda, si bé una part important de l'alumnat es va prendre el repte proposat amb interès i dedicació, enfrontant les diverses dificultats tècniques que comportava, hi va haver diversos casos d'alumnes que es desvincularen del projecte o que requerien l'atenció constant del professorat per continuar avançant.

\section{CONCLUSIONS}

Considerem que la creació conjunta d'un producte constitueix una metàfora de la idea construccionista de creació del coneixement que hem aplicat durant aquesta activitat, segons la qual el coneixement és construït per l'aprenent en la mesura que rep ajuts i treballa en comunitat per a resoldre reptes cognitius.

Pensem que l'activitat ha estat d'utilitat perquè els alumnes canviessin les seves concepcions sobre l'espai a l'Univers. Tot i que no disposem de dades quantitatives, en les converses amb els alumnes el treball amb aquestes metodologies ha fet emergir i permès corregir concepcions errònies. En particular, alguns alumnes pretenien ubicar estrelles en el recorregut del Sistema Solar (evidenciant la confusió entre dues escales d'observació) o definien les constel•lacions com a dibuixos bidimensionals reals.

El context científic proposat (la creació d'una exposició científica) ha "cridat" ítems del currículum d'altres matèries, de Llengua (comunicació oral i escrita), Matemàtiques (treball amb escales i proporcions), Tecnologia (manipulació de materials diversos) i Ciències Socials (aspectes geogràfics i d'orientació espacial) i permès el seu treball en un context rellevant per a l'alumnat. El context museístic ja s'havia usat en experiències prèvies en formats virtual i físic (Collado et al, 2016, Domènech-Casal, 2016) i constitueix una via de treball a explorar amb més profunditat, especialment pel que fa al desenvolupament de Museus físics escolars.

Des d'un punt de vista de les Competències Bàsiques (CCBB), considerem que els productes del projecte han implicat també el desenvolupament la Competència Digital, i les Competències d'Aprendre a Aprendre i d'Autonomia i Iniciativa Personal, enriquint la perspectiva d'avaluació per competències que ja es treballa al centre educatiu mitjançant el Projecte IndComp (https://projecteindcomp.wordpress.com/ ).
Per als professors que hem conduit l'activitat, la participació en aquest projecte ha estat també un aprenentatge. Hem après que un element fonamental a tenir en compte és la implicació personal de tot l'alumnat en l'activitat, i que això implica fer que els alumnes prenguin decisions, i assumeixin responsabilitats en la planificació i suport als seus companys. També que el format de treball en projectes centrats en una setmana-10 dies intensius ha d'anar acompanyat d'un treball previ de disseny del projecte compartit amb l'alumnat durant els dos mesos anteriors recolzat des de les diverses matèries i que els professors especialistes de cada àrea han d'anar passant per tots els grups mentre es desenvolupa el projecte. Pensem que no és necessari fer projectes tan complets (en aquest cas, hem desenvolupat dos projectes alhora) i que és molt necessari garantir que els alumnes tindran prou temps per a acabar les tasques i tenir una visió prèvia clara del pressupost que s'hi dedica.

Aquesta activitat ha estat desenvolupada com a aproximació al treball de l'astronomia en context amb metodologies actives i s'inclou dins la col•lecció de recursos Astrono-Me (https://sites.google.com/site/astrono2me/) juntament amb activitats prèvies desenvolupades amb un enfoc similar (Domènech-Casal, 2015, Ruiz et al, en avaluació). L'itinerari SolarSystemPathway creat pels alumnes té la pretensió de convertir-se en un equipament cultural definitiu al municipi de Granollers, al que convidem altres centres educatius de primària o secundària $a$ exposar materials creats pels seus alumnes en diversos eixos temàtics (geologia, història, meteorologia...) en el context de l'itinerari.

\section{AGRAIMENTS}

Els autors agraïm als alumnes de l'INS Granollers i les seves famílies la seva confiança i compromís amb el projecte educatiu. També volem agrair als professors Gregori Moreno, Azahara Casas i Núria Domènech els seus consells i experiència per al disseny dels projectes. Reflexions contingudes en aquest article s'emmarquen reflexions metodològiques de la xarxa d'instituts \#InstitutsProjectant i del grup LIEC (Llenguatge i Ensenyament de les Ciències) - grup de recerca consolidat (referència 2009SGR1543) de la Universitat Autònoma de Barcelona per AGAUR (Agència d'Ajuts Universitaris i de Recerca) i finançat per la Dirección General de Investigación, Ministerio de Educación y Ciencia (referència EDU-2012-38022-C02-02). Agraïm finalment al Museu de Ciències Naturals de Granollers i a l'Ajuntament de Granollers el suport rebut al projecte. 


\section{REFERENCIES}

ALFONSO, R., BAZO, C., LOPEZ, M., MACAU, M. D., RODRIGUEZ, M. L. (1995). Una aproximación a las representaciones del alumnado sobre el universo. Enseñanza de las Ciencias, 13 (3), 327-335.

CARMONA, A. (1994). Reflexiones sobre la enseñanza de la Astronomía en la E.S.O. Enseñanza de las ciencias de la tierra, 2(2-3), 404-409.

COLLADO, F., COLLADO, M., DOMÈNECH-CASAL, J. (2016). WünderKammer Project: Un contexto museístico de enseñanza de la clasificación de los seres vivos. Alambique, Didáctica de las Ciencias Experimentales (en publicació).

DOMÈNECH-CASAL, J. (2013). Los museos virtuales como recurso didáctico. Construyendo puentes digitales entre el museo y el aula. @TIC Revista d'Innovació Educativa 10, 92-100.

DOMĖNECH-CASAL, J. (2015). Eppur si muove: una secuencia contextualizada de indagación y comunicación científica sobre el sistema astronómico Sol-Tierra. Revista Eureka de Enseñanza y Divulgación de las Ciencias 12 (2), 328-340.

DOMÈNECH-CASAL, J. (acceptat). Diseño y caracterización de una secuencia contextualizada de creación del conocimiento científico alrededor de la Evolución Humana y la Paleontología. Investigación en la escuela (acceptat).

DOMÍNGUEZ, M.C., VARELA, C. (2008). Aplicación de una técnica de análisis textual a textos escolares sobre el Sistema Solar. Revista Electrónica de Enseñanza de las Ciencias 7 (1), 261-274.

GARCíA, J.L. (2014). Conocimientos astronómicos del profesorado de educación secundaria obligatoria y preferencias metodológicas para la enseñanza de astronomía. Enseñanza \& Teaching: Revista interuniversitaria de didáctica, 32(1),161198.

GONZÁLEZ, C., GARCíA, S., MARTíNEZ, C. (2015). Qué contenidos y qué habilidades cognitivo-lingüísticas emplea el profesorado de primaria y secundaria en la enseñanza de la astronomía. Enseñanza de las Ciencias, 33(2), 71-89.

GRAU, R. (2010). Altres formes de fer ciència. Rosa Sensat. Barcelona.
LEITE, C., HOSOUME, Y. (2009). Explorando a dimensao espacial na pesquisa em sensino de astronomía. Revista Electrónica de Enseñanza de las Ciencias, 8 (3), 797-811.

MAJÓ, F., BAQUERÓ, M. (2014). Los proyectos interdisciplinarios. 8 ideas clave. Editoral Graó, Barcelona.

NAVARRO, M. (2011). Enseñanza y aprendizaje de astronomia diurna en primaria mediante "Secuencias problematizadas" basadas en "mapas evolutivos". Enseñanza de las Ciencias 29(2), 163-174.

PALOMAR, R, (2013). Enseñanza y aprendizaje de la astronomía en el Bachillerato. Tesis Doctoral. Universitat de València. [http://roderic.uv.es/bitstream/handle/10550/32116/Tesis Astronomía.pdf]

POZO, J. I., GÓMEZ, M.A. (2010). Por qué los alumnos no comprenden la ciencia que aprenden. Alambique, Didáctica de las Ciencias Experimentales 66, 73-79.

RUIZ, S., SERRA, C., DOMÈNECH-CASAL, J. (en avaluació). Mission to stars: un proyecto de Ciencia y Tecnología alrededor de la astronomía, las misiones espaciales y la investigación científica para asomarse "ahí afuera". Revista Eureka de Enseñanza y Divulgación de las Ciencias.

SOLBES, J., PALOMAR, R. (2011). ¿Por qué resulta tan difícil la comprensión de la astronomía a los estudiantes? Didáctica de las ciencias experimentales y sociales, 25, 187-211.

VARELA, M., PÉREZ, U., ULLA, A.M., ARIAS, A. (2012). Problemáticas del proceso de enseñanza y aprendizaje de la astronomía. Boletín das ciencias, 76, 107-109.

VÍLCHEZ-GONZÁLEZ, J. M., RAMOS-TAMAJÓN, C. M. (2015). La enseñanza-aprendizaje de fenómenos astronómicos cotidianos en la Educación Primaria española. Revista Eureka sobre Enseñanza y Divulgación de las Ciencias 12(1), 2-21.

\section{NOTES}

[1] Webs amb les tasques dels projectes: xyzStars Exhibition: 
https://sites.google.com/site/xyzstarsexhibition/ ; SolarSystemPathway https://sites.google.com/site/solarsystempathway/

[2] El programa Stellarium és de descàrrega gratuïta i ús lliure:

http://www.stellarium.org/ca/
[3] Vídeo del reportatge sobre l'Exposició xyz-Stars realitzat per Vallès Televisió:

http://votv.xiptv.cat/granollers/capitol/granollersacull-una-mostra-de-l-univers-feta-per-alumnesd-eso 